\title{
DIAGNÓSTICO DO GERENCIAMENTO DOS RESÍDUOS SÓLIDOS GERADOS NA PRAÇA DE ALIMENTAÇÃO EM UMA UNIVERSIDADE DO INTERIOR DO ESTADO DE SÃO PAULO
}

\section{DIAGNOSIS MANAGEMENT OF SOLID WASTE GENERATED IN THE FOOD COURT AT A UNIVERSITY IN THE STATE OF SÃO PAULO}

Carolina Guarizzi Sanches Oliveira ${ }^{1}$, Lorrayne Mendes Marques ${ }^{2}$, Leila Maria Couto Esturaro Bizarro ${ }^{1}$, Leila Maria Sotocorno e Silva ${ }^{1}$

\footnotetext{
${ }^{1}$ Universidade do Oeste Paulista - UNOESTE, Curso de Engenharia Ambiental, Presidente Prudente - SP. ${ }^{2}$ Universidade Estadual de Londrina - UEL, Pós Graduanda no Curso de Engenharia de Segurança do Trabalho. E-mail: lorrayne marques@hotmail.com
}

RESUMO - O ambiente acadêmico possui vínculo com grande quantidade de pessoas e suas atividades resultam na geração de resíduos sólidos, sendo necessário um adequado gerenciamento, pois o seu manejo incorreto acarreta em problemas ambientais e de saúde pública. Este trabalho teve por objetivo diagnosticar o gerenciamento dos resíduos sólidos gerados na praça de alimentação do Campus II da Universidade do Oeste Paulista em Presidente Prudente - SP. O procedimento adotado foi de identificação do atual sistema de gerenciamento e caracterização dos resíduos sólidos, analisando-os quantitativamente e qualitativamente. As análises ocorreram durante uma semana dos meses de junho, julho e agosto, com pesagens diárias e caracterização duas vezes por semana para análise de sua gravimetria. Os resultados constataram que a geração de resíduos sólidos variou conforme o fluxo de pessoas no local e que algumas etapas do sistema de gerenciamento deveriam ser modificadas para melhor desempenho ambiental.

Palavras-chave: Resíduos sólidos; geração; análise gravimétrica; diagnóstico; gerenciamento.

ABSTRACT - The academic environment has link with loads of people and their activities result in the generation of solid waste, proper management is necessary because its mishandling leads to environmental problems and public health. This study aimed to diagnose the management of solid waste generated in the food court of the Campus II of the University of Oeste Paulista in Presidente Prudente - SP. The procedure adopted was to identify the current management system and characterization of solid waste, analyzing them quantitatively and qualitatively. The analyzes were conducted for a week for the months of June, July and August, with daily weighing and characterization twice weekly for analysis of its gravity. The results found that solid waste generation varied according to the flow of 
people on site and that some parts of the management system should be modified to better environmental performance.

Keywords: Solid waste; geration; gravimetric analyze; diagnostic; management.

Recebido em: 01/09/2014

Revisado em: 10/09/2014

Aprovado em: 15/09/2014 


\section{INTRODUÇÃO}

Os fatores que estimulam a grande geração de resíduos sólidos são os padrões de consumo e de produção, sendo que a grande parte desses resíduos é constituída por matéria-prima que poderia ser reinserida no processo produtivo, como é o caso dos materiais recicláveis, e também por matéria orgânica, basicamente alimentos, que devido às más condições de armazenamento e ao desperdício, tanto no preparo quanto no consumo, acaba por virar rejeito ao invés de transformar-se em compostos orgânicos. (ASSOCIAÇÃO BRASILEIRA DE ENGENHARIA SANITÁRIA E AMBIENTAL, 2000).

Dentre todos os tipos de resíduos, os resíduos sólidos merecem notoriedade por sua substancial parcela dentre todas as categorias de resíduos gerados, e quando mal gerenciados, tornam-se um problema sanitário, ambiental e social. O conhecimento das fontes e dos tipos de resíduos sólidos, através de dados da sua composição e da sua taxa de geração, é o instrumento básico para o gerenciamento dos mesmos (KGATHI; BOLAANE, 2001 apud CABRAL s/d).

Destaca-se neste princípio a relevância da apuração da qualidade com que se gerenciam os resíduos sólidos gerados para que estes não interfiram negativamente no controle da preservação ambiental e valorize o bem estar das pessoas que frequentam o meio em questão. Galvão (2012) ressalta que, mesmo que a geração do resíduo não possa ser evitada, que ainda assim seu tratamento é indispensável.

A Universidade do Oeste Paulista em Presidente Prudente - SP tem como missão desenvolver a educação em um ambiente inovador e crítico reflexivo, nas diversas áreas do conhecimento científico, humanístico e tecnológico, que pode contribuir para a formação de profissionais cidadãos comprometidos com a responsabilidade social e ambiental.

A prática de atividades ligadas à responsabilidade ambiental no âmbito acadêmico é importante para ser exemplo diante a sociedade, pois através de programas voltados à Educação Ambiental de docentes, discentes e funcionários, é possível ter um desenvolvimento sustentável de forma que todos contribuam para um ambiente de boa qualidade, que beneficia os usuários e o meio ambiente.

O presente trabalho teve por objetivo realizar o diagnóstico dos resíduos sólidos gerados na praça de alimentação do Campus II da Universidade do Oeste Paulista Unoeste em Presidente Prudente.

\section{METODOLOGIA}

\subsection{Caracterização da área de estudo}


Primeiramente o projeto foi enviado para o Comitê de Ética em Pesquisa (CEP) do tipo PEIC, devidamente analisado e aprovado sob protocolo: 1546, na data de 15 de fevereiro de 2013.

O estudo foi realizado na praça de alimentação no Campus II da Universidade do
Oeste Paulista - UNOESTE, localizada na Rodovia Raposo Tavares, Km 572, na cidade de Presidente Prudente, interior do estado de São Paulo. O local do estudo localiza-se nas coordenadas geográficas de: Latitude $22^{\circ} 06^{\prime} 57,96^{\prime \prime} \mathrm{S}$ e Longitude $51^{\circ} 26^{\prime} 52,56^{\prime \prime} \mathrm{O}$ (Google Earth).

Figura 1. Croqui de identificação do Campus II - Universidade do Oeste Paulista - UNOESTE.

\section{Campus II}

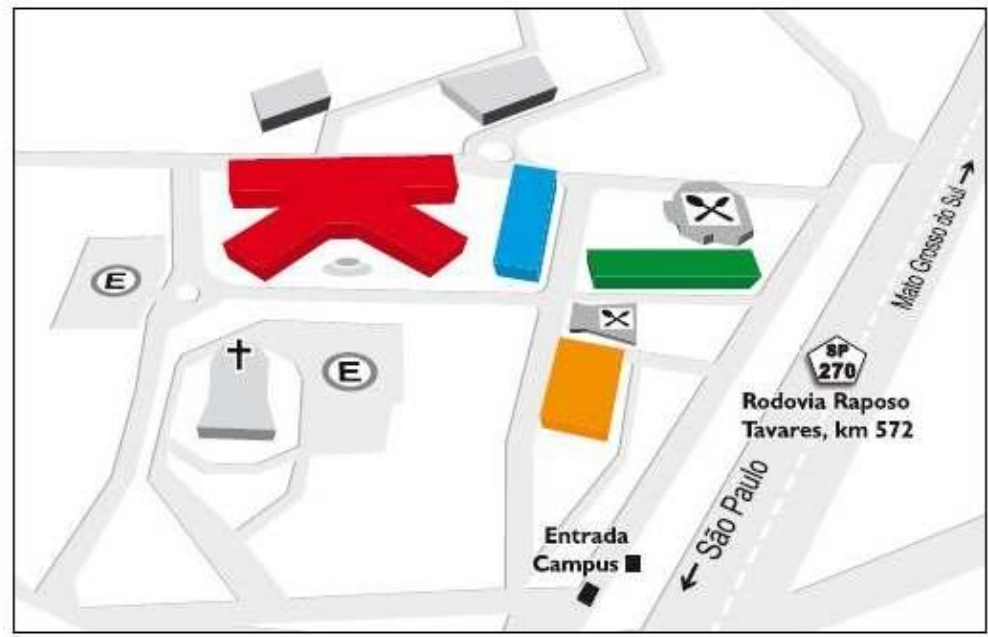

$\begin{array}{ll}\text { Salão Limoeiro } & \text { Bloco B2 } \\ \text { Bloco Bl } & \text { Bloco B3 }\end{array}$

Fonte: Unoeste, 2013, grifo nosso.

\subsection{Diagnóstico do gerenciamento dos} resíduos sólidos

Foram realizadas visitas à praça de alimentação para analisar o seu funcionamento e observação das formas de geração, armazenamento, coleta, transporte e destinação dos resíduos sólidos. Além disso, possibilitou a captura de imagens fotográficas do ambiente, e entrevistas com os responsáveis pelos estabelecimentos e do setor de limpeza, para a coleta de informações questionando-os sobre o gerenciamento do local.

\subsubsection{Caracterização dos resíduos sólidos}

Para que fossem especificadas as gerações dos resíduos sólidos da praça de alimentação em períodos distintos, foi realizada análise quantitativa para obter através das pesagens os valores totais dos resíduos gerados e análise gravimétrica para 
determinar em porcentagens os valores distintos de cada tipo de resíduo separado.

A caracterização dos resíduos sólidos foi efetuada no Laboratório de Engenharia Civil da Universidade do Oeste Paulista UNOESTE, em Presidente Prudente - SP, no ano de 2013, nos períodos de 17 a 23 de junho (vestibular), de 22 a 28 de julho (férias) e 19 a 25 de agosto (letivo), que equivaleu a uma semana de cada mês.

\subsubsection{Análise quantitativa}

\section{- $\quad$ Coleta e pesagem dos}

resíduos sólidos

Para a quantificação dos resíduos sólidos, os sacos plásticos de acondicionamento foram etiquetados com fita colorida para diferenciá-los dos demais durante todos os dias de geração diferentes apenas das etiquetas da sexta-feira, sábado e domingo (em caso de evento atípico), já que os mesmos eram coletados juntos na segunda-feira, para que ao serem transportados pela equipe de trabalho junto aos resíduos de outros setores do campus pudessem ser identificados e descarregados isoladamente no Laboratório de Engenharia Civil.

Foram realizadas pesagens diárias durante uma semana de cada período estabelecido (atípico, de férias e letivo). Os resíduos sólidos eram coletados e pesados no dia posterior à sua geração na praça de alimentação. Todos os resíduos gerados durante as segundas-feiras foram coletados e pesados às terças-feiras, e assim sucessivamente. Para completar os sete dias correspondentes a uma semana, nas segundas-feiras seguintes houve a continuação desta tarefa para aferição dos resíduos das sextas-feiras (visto que nesse caso não foi realizada a coleta de resíduos no campus aos sábados), sábado, e domingo em caso de evento atípico.

Entre as terças e sextas-feiras o período de geração de resíduos sólidos compreendeu o intervalo das $12 \mathrm{~h}: 00 \mathrm{~m}$ de um dia até o dia seguinte nesse mesmo horário, a coleta foi realizada em seguida; aos sábados não houve coleta e pesagem, portanto os resíduos referentes às sextasfeiras foram mantidos na lixeira coletora e identificados para que não se misturasse aos gerados aos sábados; a geração aos sábados iniciou a partir das $12 \mathrm{~h}: 00 \mathrm{~m}$, devido às adequações do trabalho ao planejamento de horários utilizados pelo setor de coleta e foram todos coletados às $9 \mathrm{~h}: 00 \mathrm{~m}$ das segundas-feiras, em conformidade ao planejamento de coleta da universidade.

\section{- $\quad$ Análise gravimétrica}

As pesagens foram realizadas todos os dias da semana e a caracterização somente as terças e quintas-feiras nos meses de julho e agosto, em junho devido ao fato de ser em 
evento atípico, foi determinado na quarta e segunda-feira.

A gravimetria foi realizada pela caracterização, com o intuito de obter a composição dos resíduos identificados e a comparação entre a quantidade de cada resíduo sólido gerado, sua execução foi por triagem manual, os resíduos foram dispostos em uma lona, para identificação e segregação, em seguida separados em grupos de acordo com sua característica: alumínio, orgânico, papel, plástico, rejeito, sanitário, vidro e outros materiais. Os componentes existentes foram pesados por grupo para determinação de sua quantidade em relação ao peso total da amostra.

Com a finalização das pesagens e caracterização no dia, os sacos foram armazenados em um local específico para serem posteriormente coletados pelos responsáveis e levados para a destinação final como era realizado comumente.

\subsection{Análise de Resultados}

As análises dos resultados se efetuaram por estatística básica, fundamentada na matemática aplicada, que auxiliou a interpretação de dados após coleta de informações, além disso, a ferramenta do Windows, o Microsoft Excel, serviu como base na criação de gráficos e tabelas.

A avaliação da qualidade do gerenciamento de resíduos sólidos da praça de alimentação do Campus II foi à conclusão de todo o diagnóstico realizado, que permitiu o reconhecimento do manejo, que poderia este ser adequado ou não. Em caso de apontamento negativo, foram indicadas opções de melhoria, através de propostas.

\section{RESULTADOS}

\subsection{Infraestrutura da praça de alimentação}

A praça de alimentação conta com 7 quiosques, sua distribuição no espaço acontece de forma circular no interior da área que abrange mesas e assentos; possui também sanitários para os usuários. Cada quiosque possui em média 2 funcionários, cada um responsável pelo seu próprio estabelecimento. O funcionamento ocorre de segunda à sexta, durante o período matutino, vespertino e noturno, aos sábados somente matutino e vespertino, e aos domingos apenas em eventos atípicos, que requeiram seu funcionamento.

\subsection{Sistema de gerenciamento dos resíduos} sólidos

O gerenciamento dos resíduos gerados na praça de alimentação representadas pelo fluxograma na Figura 2 é de responsabilidade da universidade como instituição privada que possui domínio sobre as suas atividades internas e os locatários dos quiosques responsáveis pela etapa operacional. 
Figura 2. Fluxograma do atual gerenciamento dos resíduos sólidos da praça de alimentação do Campus II - Unoeste.

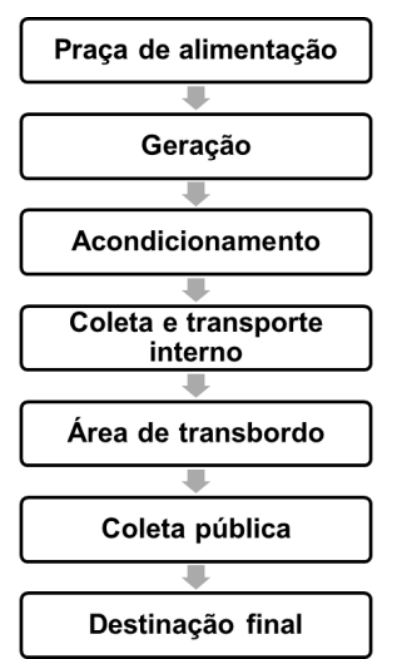

Fonte: As autoras (2014).

\subsubsection{Geração}

Os resíduos sólidos gerados na praça de alimentação são provenientes da comercialização de produtos alimentícios e das atividades decorrentes do local. Há grande variedade de produtos para comercialização e, existe uma semelhança entre os produtos disponíveis nos quiosques, são elas as vendas constituídas basicamente de salgados, doces, biscoitos, sanduíches naturais e bebidas naturais e industrializadas. Os resíduos consequentes dessa atividade são: guardanapos, copos, plásticos, cartonados (embalagem longa-vida), alumínio, papelão, matéria-orgânica (varrição e restos de alimentos) e rejeitos de banheiro.
Por meio da análise quantitativa da geração dos resíduos sólidos, pôde-se mensurar que todas as semanas estudadas possuíram variação diária de geração, assim como entre cada período (atípico, de férias e letivo), que determinou a relação da geração de resíduos em função da presença de pessoas no Campus.

O Quadro 1 apresenta os valores dos resíduos sólidos gerados e pesados diariamente e a média semanal, entre os dias 17 e 23 de junho, 22 e 27 de julho, e 19 e 24 de agosto de 2013. 
Quadro 1. Pesagens dos resíduos sólidos gerados nos meses de junho, julho e agosto de 2013.

\begin{tabular}{|c|c|c|c|c|c|c|c|c|c|c|}
\hline \multicolumn{10}{|c|}{ Peso dos resíduos sólidos (Kg) } \\
\hline Período & $\begin{array}{c}\text { Dia } \\
\text { Mês }\end{array}$ & $\begin{array}{c}\text { Segunda- } \\
\text { feira }\end{array}$ & $\begin{array}{c}\text { Terça- } \\
\text { feira }\end{array}$ & $\begin{array}{c}\text { Quarta- } \\
\text { feira }\end{array}$ & $\begin{array}{c}\text { Quinta- } \\
\text { feira }\end{array}$ & $\begin{array}{c}\text { Sexta- } \\
\text { feira }\end{array}$ & Sábado & Domingo & $\begin{array}{c}\text { Total } \\
\text { semanal }\end{array}$ & Média \\
\hline $\begin{array}{c}\text { Atípico } \\
\text { (vestibular) }\end{array}$ & $\begin{array}{c}\text { Junho } \\
\text { (17 à 23) }\end{array}$ & 68,960 & 55,440 & 48,550 & 149,490 & 42,470 & 10,730 & 152,790 & 375,640 & 75,490 \\
\hline Férias & $\begin{array}{c}\text { Julho } \\
\text { (22 à 27) }\end{array}$ & 5,340 & 4,410 & 4,060 & 3,010 & 5,860 & 9,880 & - & 32,560 & 5,470 \\
\hline Letivo & $\begin{array}{c}\text { Agosto } \\
\text { (19 à 24) }\end{array}$ & 297,780 & 462,110 & 326,83 & 260,12 & 226,48 & 59,34 & - & $1.632,66$ & 272,110 \\
\hline
\end{tabular}

Fonte: As autoras (2014).

Através da análise gravimétrica calculada após a caracterização dos resíduos sólidos foi possível identificar a média entre os dois dias de caracterização de cada período, que demonstrou o contraste entre as porcentagens dos diferentes tipos de resíduos sólidos em seus respectivos períodos.

Os resíduos sólidos foram separados em grupos, conforme sua composição, apresentados a seguir:

* Alumínio: papéis, tampas de garrafa e latas de bebidas;

* Orgânico: resto de alimentos comercializados e de frutas utilizadas para preparo de sucos e varrição (composta por folhas de árvores e terra);

Papel: papéis, papelões e embalagens Longa Vida;
Plástico: isopores, sacolas, filme plástico, copos descartáveis, canudos e embalagens plásticas de biscoitos, sachês de molhos e outras;

* Rejeito: resíduos gerados nos sanitários, como: papéis higiênicos e toalha; guardanapos usados e papéis contaminados;

* Vidro: garrafas de bebidas, pratos e copos quebrados;

* Outros: resíduos não pertencentes aos grupos acima.

O gráfico 1 apresenta a média dos resíduos sólidos identificados entre os dois dias de caracterização, que ocorreram nos dias 19 e 24 de junho, 23 e 25 de julho, e 20 e 22 de agosto de 2013. 
Gráfico 1. Média gravimétrica dos resíduos sólidos.

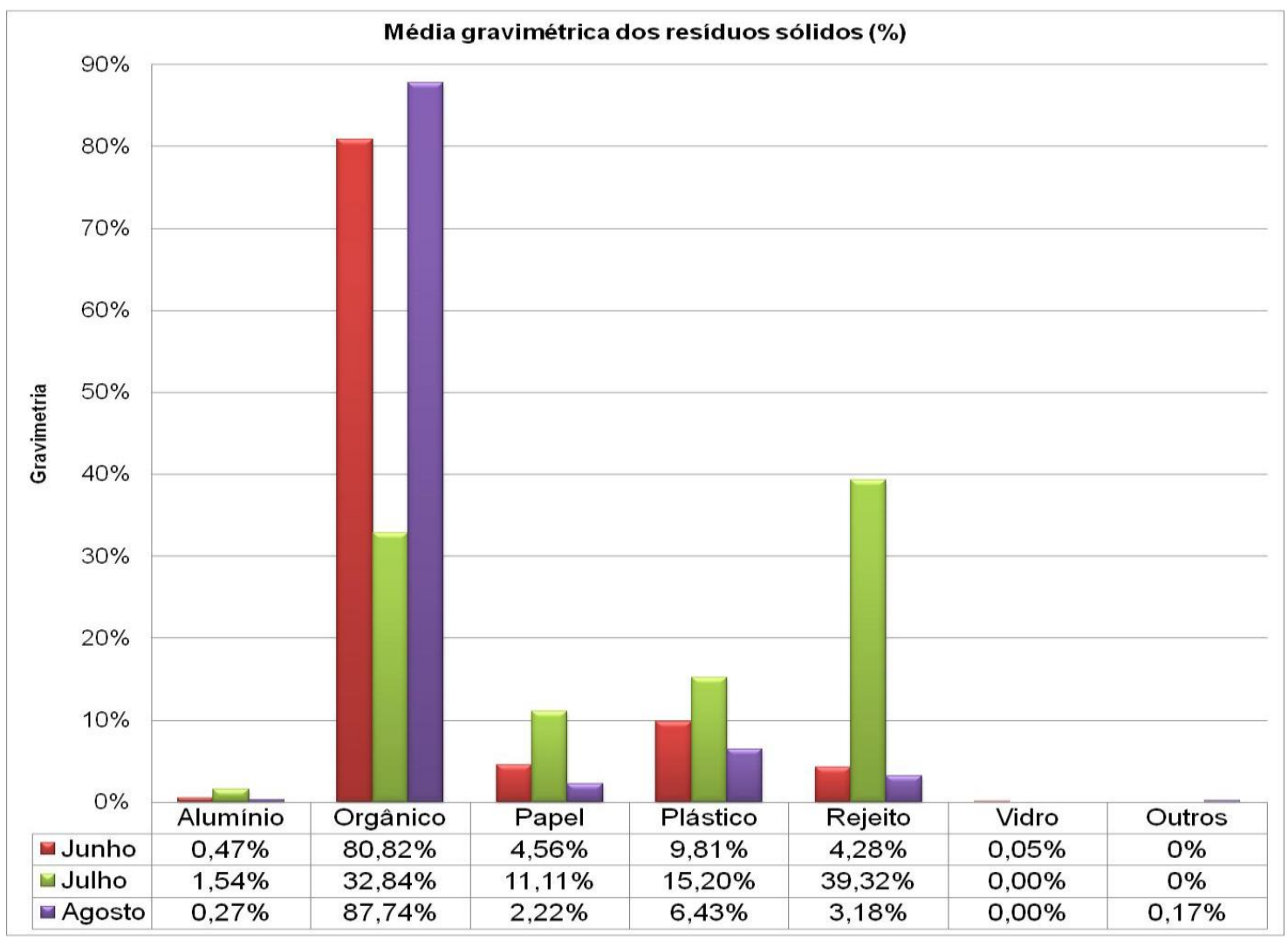

Fonte: As autoras (2014).

A porcentagem foi semelhante entre alguns resíduos caracterizados quando comparados entre períodos, por isso foram perceptíveis quais os tipos de produto que possuem o maior consumo e geração de resíduos.

\subsubsection{Segregação e Acondicionamento}

Existe apenas um coletor na praça de alimentação que abrange as respectivas cores de identificação para segregação adequada dos materiais, porém os recipientes possuem baixa capacidade de armazenamento, um fato que impede com que a segregação dos resíduos sólidos gerados no local seja realizada de fato, pois no momento que o coletor que separa certo resíduo está carregado, os usuários acabam por depositar os resíduos que ali seriam descartados em qualquer outro coletor com especificação diferente. Além disso, os resíduos não são separados nos outros coletores existentes, após sua geração, portanto desde os resíduos gerados no coletor com identificação, até os presentes nos coletores tradicionais, são misturados pela etapa de acondicionamento realizada no local, que reúne todos os resíduos sólidos existentes em sacos plásticos sem identificação e separação, que impossibilita a diminuição do volume dos resíduos sólidos gerados. O coletor para segregação é dividido 
nas cores e consequentemente os materiais: Verde - vidro; Azul - papel; Vermelho plástico; Amarelo - metal; Cinza - outros.

O acondicionamento dos resíduos gerados na parte externa dos quiosques é realizado em vários recipientes revestidos por saco plástico preto de 15 litros, sem tampa, dispostos em frente aos quiosques. Cada quiosque possui um recipiente grande, com tampa, com sacos plásticos de 60 litros para armazenar os resíduos gerados na parte interna dos quiosques.

Os sacos, após a etapa de acondicionamento dos resíduos na praça de alimentação, são postos na lixeira coletora que é posicionada na parte de trás da praça de alimentação localizada ao lado do estacionamento.

\subsubsection{Coleta e transporte}

A coleta dos resíduos no coletor é realizada pela equipe de trabalho do setor da jardinagem, responsável para essa função, admitida para a Universidade toda. A coleta ocorre na segunda-feira às $08 \mathrm{~h}: 00 \mathrm{~m}$ e de terça à sexta-feira às $12 \mathrm{~h}: 00 \mathrm{~m}$, e aos sábados e domingos somente quando ordenado. $\mathrm{O}$ transporte utilizado é um trator com carroceria.

\subsection{4 Área de transbordo}

Os resíduos são descarregados em um pequeno galpão próximo ao portão 2 de entrada da Universidade. É um local fechado que possui portões de acesso pelo lado interno e externo da Universidade, para que sejam coletados pelo serviço de coleta pública da cidade.

O acúmulo de sujeira e odor no depósito é ocasionado pelos resíduos que são espalhados no local quando os sacos se rompem pelo armazenamento de resíduos em excesso e/ou não são devidamente lacrados na etapa do acondicionamento. O chorume proveniente dos resíduos orgânicos misturado com resto de líquidos acarreta em vazamento, que gera mau cheiro e aparência desagradável. Esse fato é resultado da falta de uma separação adequada dos resíduos, pois ocorre a mistura dos resíduos sólidos.

\subsubsection{Coleta Pública}

A coleta dos resíduos sólidos no pequeno galpão é de responsabilidade da empresa que realiza a limpeza pública do município de Presidente Prudente, a Companhia Prudentina de Desenvolvimento - PRUDENCO. Para isso utiliza o método de coleta convencional, que recolhe todos os resíduos gerados, sem distinção de materiais, e armazenam no caminhão. Os dias para recolhimento dos resíduos na Universidade ocorrem na segunda, quarta e sexta-feira. 


\subsubsection{Destinação final}

Após a coleta pública, os resíduos são destinados para o lixão do município de Presidente Prudente - SP, o qual recebe diariamente os resíduos coletados em toda a cidade, que inclui lixo domiciliar e o restante de lixo urbano (resíduos de varrição, construção civil, corte de gramas e outros).

\section{DISCUSSÕES}

- Quanto ao gerenciamento de resíduos sólidos

O atual gerenciamento de resíduos sólidos tem sido inadequado por não atender os processos apropriados de: redução e segregação na fonte de geração, acondicionamento, tratamento e destinação final. Essas etapas devem ser eficientes, pois estão interligadas com fatores sociais, econômicos e ambientais, e podem resultar em benefícios multidisciplinares quando bem planejados e desenvolvidos além de acarretar em menor quantidade dos resíduos dispostos no meio ambiente e minimizar dos impactos causados.

\section{- Quanto à geração}

A semana do mês de agosto (período letivo) apresentou maior quantidade de resíduos quando comparada às outras. Esse fato pode ser explicado devido ao número de pessoas que retornaram às atividades acadêmicas e a inclusão de novos alunos para o segundo semestre letivo.

O mês de junho obteve um decréscimo de geração devido ao encerramento das aulas, que aconteceram basicamente apenas as últimas avaliações semestrais até o dia 20 do mês, conforme determinado pelo calendário da Universidade para os respectivos cursos existentes. A caracterização da semana deste mês destinou-se à análise de geração do vestibular de inverno, um evento atípico que confirmou a suspeita de haver uma geração incomum e excessiva diante dos outros dias da semana, ele aconteceu na segunda quinzena de junho, em uma quinta-feira para o curso de medicina e domingo para os demais cursos.

No mês de julho (férias) os valores decresceram quando comparados aos outros meses devido ao encerramento das atividades para os cursos de graduação e superior tecnológico e, permanece em funcionamento apenas atividades administrativas e de cursos de pósgraduação.

\section{- Quanto à gravimetria}

O mês de julho foi o único que se diferenciou, que obteve o rejeito como resíduo com maior porcentagem, que resultou em $39,32 \%$ da média total, sendo $7,03 \%$ de resíduos contaminados e $92,97 \%$ de 
resíduos sanitários. Em junho o valor foi de 4,28\%, dividido em $28,5 \%$ de resíduos contaminados e $71,5 \%$ de resíduos sanitários, e por fim no mês de agosto o total foi de $3,18 \%$ da média total, destrinchado em $53,9 \%$ de resíduos contaminados e $46,1 \%$ de resíduos sanitários.

Essa alteração da ordem de maior geração de rejeitos no mês de julho quando comparado com os outros meses, pode ser consequência da diminuição do movimento da praça de alimentação devido às férias, pelo encerramento do semestre letivo, e posteriormente diminuir o consumo pela falta de frequência de pessoas que se difere de acordo com a característica de cada período, porém há a permanência dos funcionários dos quiosques, que fazem com exista geração de resíduos sanitários, pela utilização pelos mesmos do banheiro, de modo que a utilização dos sanitários não se dá apenas pelo fluxo de pessoas que frequentam o local, mas sim pela necessidade momentânea das pessoas.

A presença de resíduos orgânicos representou o maior porcentual nos meses de junho com $80,82 \%$ e agosto com $87,74 \%$, já no mês de julho se destacou como segundo mais gerado que ficou com $32,84 \%$. É notável que a presença de resíduos orgânicos é em grande maioria devido ao elevado consumo de produtos alimentícios, que variam entre restos de salgados e doces, frutas, pó de café, e também as folhas que são provenientes da varrição da praça de alimentação, e esse tipo de resíduo tem tendência a aumentar quando se há maior fluxo de pessoas no local.

O componente que tem segundo maior porcentual é o plástico, com 9,81\% em junho e $6,43 \%$ em agosto que incluiu um objeto atípico dos outros períodos, um assento de vaso, e mesmo que não foi gerado com frequência, não deve ser desconsiderado, por ter características plásticas que pode ser reciclado. No mês de julho permaneceu em terceiro na colocação, que ficou com $15,20 \%$. Por ser um produto utilizado em diferentes formas, pela disponibilidade de itens que podem ser fabricados com esse material, resulta em uma diversidade de resíduos gerados, entre eles os copos e canudos descartáveis utilizados para consumo de bebidas em geral, bem como as embalagens de alimentos, já que a maior parte dos produtos precisam ser protegidos para evitar contaminação antes de serem consumidos, que acarreta em maior geração de resíduos plásticos.

O resíduo de alumínio gerado ficou como o quinto resíduo mais gerado, nos meses de junho e julho, obteve variação da porcentagem entre $0,47 \%$ e $1,54 \%$, e no mês de agosto esta com a porcentagem de $0,27 \%$, que o deixou em último na listagem. 0 alumínio é um resíduo pouco identificado 
pela quantidade baixa de consumo de materiais com essa característica.

A geração do grupo de papéis no mês de junho é de $4,56 \%$, por isso ficou como o terceiro resíduo mais gerado, já em julho e agosto obteve uma geração de 11,11\% e $2,22 \%$ respectivamente, por isso ficou em quarto na colocação de geração, porém houve uma diferenciação nas porcentagens, que foi notável o elevado porcentual de julho, porém isso é possível devido à reposição de estoque e organização do estabelecimento para o próximo semestre, que foram descartadas muitas caixas de papel e papelão que servem como embalagens para alguns dos produtos comercializados.

A presença de vidro foi evidenciada apenas durante a caracterização do mês de junho, que teve como porcentagem o valor de $0,05 \%$, porém este fator não deve ser considerado como excludente de sua existência, pois sua geração não é constante, mas é válida, devido à utilização de materiais que se quebram ou que não são mais utilizados, e são então descartados pela falta de opção.

Apenas no mês de agosto houve a presença da separação de materiais incomuns aos até então caracterizados. Esse fato deve ainda considerar que diariamente resíduos atípicos podem ser produzidos, mesmo que em pequenas quantidades, por isso se justifica a importância de várias semanas e períodos de estudo, para conferir as peculiaridades da geração de resíduos sólidos. O grupo outros foi composto de materiais como: panos, porcelana, relógio, esponja de fibra sintética e luvas de borracha, que totalizou em $0,17 \%$ do total de resíduos sólidos.

Ressalta-se que os resíduos sólidos gerados na praça de alimentação são classificados quanto à sua periculosidade, segundo a ABNT - NBR 10004:2004 em não perigosos - Classe II e se enquadram na Classe II A - não-inertes.

A falta de planejamento interno dos comerciantes ocasiona a geração desnecessária de resíduos que são provenientes do consumo inconsciente em relação às questões ambientais, além de frequentemente os alimentos serem descartados pelos proprietários dos estabelecimentos, por conta da má organização interna em questões de armazenamento e de ultrapassarem o prazo de validade, que terminam por perderem o produto e seu próprio lucro e, contribui para um maior impacto ambiental e financeiro.

\section{- Quanto à segregação e} acondicionamento

O acondicionamento não possui uma organização funcional, de forma que a grande quantidade de resíduos sólidos 
gerados é descartada em pequenos coletores e com o intenso fluxo de pessoas que consumem nos quiosques, constantemente os estabelecimentos se atentam em recolher e transferir os resíduos para um recipiente maior, o coletor unitário de "60" litros.

Optam por vários recipientes menores por serem visualmente melhor para a fachada do quiosque. No entanto, pelo fato de haver o acúmulo de líquidos e outros alimentos que impregnam nos sacos, cada um deles dos 4 coletores pequenos existentes em cada quiosque são trocados diariamente, assim como são preenchidos em média 3 sacos de 50 litros por dia de resíduos, denotado desperdício, pois a quantidade de resíduos gerados é grande e precisaria de apenas recipientes maiores e adequados à cada tipo de resíduo.

A lixeira coletora de resíduo é localizada em uma área onde possui circulação de pessoas e automóveis, já que está instalado em um dos estacionamentos da Universidade. Esse fato se torna um ponto negativo, porque a capacidade do coletor não é suficiente para a demanda de sacos de resíduo gerados diariamente, quando analisado os dias de maior movimentação, por isso os sacos são alocados nas proximidades, por não haver espaço suficiente no coletor. Outro fator é a poluição visual e odor, causado por ser um recipiente aberto, sem tampa, com laterais e fundo sem revestimentos, portanto está propício à proliferação de insetos, pois alguns resíduos se espalham por conta da falta de lacre nos sacos, e também há animais, como cães e gatos, que circulam próximo à lixeira coletora.

\section{PROPOSTAS}

A partir dos conhecimentos adquiridos na graduação, serão apresentadas algumas propostas para melhorias no sistema de gerenciamento dos resíduos sólidos da praça de alimentação do Campus II, com o intuito de solucionar os problemas existentes por meio de sugestões ambientalmente corretas, que incluem questões educacionais e ações sustentáveis que não exijam grandes investimentos para modificações da estrutura atual.

\subsection{Educação Ambiental}

O projeto educacional sobre meio ambiente teria ênfase em resíduos sólidos através de meios interativos com os frequentadores do local. O método seria empregado em formas atrativas como: adesivos recreativos nas mesas da praça, informes orientadores em locais estratégicos realizados em conjunto com a Faculdade de Comunicação Social "Jornalista Roberto Marinho" de Presidente Prudente - FACOPP e divulgação na página da universidade sobre a inovação implantada na praça. Teria como 
intuito sensibilizar e incentivar a comunidade acadêmica em mudar os hábitos, de forma que contribuísse com as questões ambientais.

A educação ambiental permitiria o sucesso das adequações propostas nas etapas do gerenciamento.

\subsection{Gerenciamento dos resíduos sólidos}

\section{- $\quad$ Geração}

A redução na fonte de geração e a adoção de produtos sustentáveis, que exijam menores quantidades de embalagens, seriam a alternativa mais viável para a minimização dos impactos ambientais causados pelos resíduos sólidos. Ambas opções evitaria o desperdício de produtos inutilizados pelo consumidor e a utilização de recursos naturais na fabricação do produto.

\section{- Segregação e acondicionamento}

Propõe-se que os coletores comuns espalhados e o seletivo, atualmente encontradas nos quiosques, sejam substituídos por coletores seletivos com capacidade ampliada, de forma que sejam instalados em pontos estratégicos.

Para resguardar a higiene nesse ato, seria adequado que os coletores seletivos fossem fechados, que obtivessem apenas uma abertura frontal para inserir os resíduos, para evitar a proliferação de vetores de doenças, atração de insetos, e a perturbação do gerador em ter que realizar esforço para abrir o coletor ou sujar as mãos.

A capacidade de armazenagem dos coletores deveria ser de aproximadamente 100 litros, para poupar o trabalho de recolher os sacos que se encheriam com rapidez e o uso excessivo de sacos plásticos. Seria indicado que cada coletor exibisse além da identificação básica de segregação, um informativo, que constasse quais resíduos poderiam ser colocados em cada uma.

A proposta é que mantivessem 3 tipos de coletores em cada ponto designado, elas poderiam ser divididas em cores diferenciadas, os quais são: Recicláveis (azul): Papel, plástico, metal e vidro; Orgânicos (preto): Restos de alimentos e varrição e; Não recicláveis (cinza): Rejeitos.

Para diferenciação dos resíduos na hora da destinação para tratamento ou disposição final seria aconselhável que houvesse uma pequena mudança quanto à identificação dos sacos plásticos, de forma que fosse adotada a cor do saco conforme a cor do coletor.

É aconselhado que os coletores grandes para o qual todos os resíduos são acondicionados antes da coleta final e transporte sejam substituídos por contêineres ampliados, com abertura na parte frontal e com tampa superior para abrigar melhor os sacos contra insetos, preveniria o odor, deixaria um aspecto mais 
higiênico e confortável visualmente, além de que evitaria a exposição aos eventos climáticos.

\section{- $\quad$ Coleta e transporte}

A coleta e transporte dos resíduos sólidos presentes no contêiner, na parte interna poderiam continuar como ocorre atualmente.

Os resíduos sólidos recicláveis e os rejeitos seriam coletados dos contêineres e transportados para a área de transbordo para armazenamento temporário. Já os resíduos orgânicos seriam encaminhados para realizar a compostagem como forma de tratamento, em um local específico na universidade.

A responsabilidade pela coleta dos resíduos recicláveis na área de transbordo seria da cooperativa da cidade ou como segunda opção poderia ser realizada parceria com organizações privadas que fariam a reciclagem.

Os rejeitos seriam de responsabilidade da empresa que realiza a limpeza pública municipal, visto que seriam encaminhados para o lixão da cidade como é realizado diariamente.

\section{- $\quad$ Área de transbordo}

A disposição dos resíduos no pequeno galpão para coleta municipal deveria manterse separada dos designados para a reciclagem. Seria necessário dividir o espaço em dois ambientes, pois os resíduos estariam identificados pela coloração dos sacos plásticos, de forma que de um lado permaneceriam os rejeitos e o restante dos resíduos gerados nas outras áreas do campus, e do outro lado seriam reunidos os resíduos recicláveis. Essa disposição teria o intuito de facilitar a identificação dos resíduos no momento da coleta pelas empresas responsáveis.

\section{- Tratamento para os resíduos orgânicos}

Os resíduos orgânicos seriam dispostos em uma área existente na universidade, denominado antigo minhocário, para realizar a compostagem como tratamento. Poderia ser uma central de compostagem que abrangeria os resíduos orgânicos provenientes da praça de alimentação.

O acompanhamento na central de compostagem ocorreria diariamente, por meio de aulas a campo, atividades obrigatórias, projetos de pesquisa e/ou extensão, ou estágios supervisionados.

\section{CONCLUSÃO}

Os resultados do diagnóstico demonstraram que não existe preocupação com a quantidade de resíduos gerados e não há uma política voltada para o 
gerenciamento ambiental dos resíduos sólidos.

A quantificação dos resíduos sólidos apresentou variação diária e entre os períodos letivo, de férias e atípico, que foi proporcional ao fluxo de pessoas no campus, porém a análise gravimétrica demonstrou semelhança em todos os períodos. De acordo com a gravimetria, os resíduos sólidos caracterizados que obtiveram a média mais elevada de geração entre os períodos, foram respectivamente: orgânicos que atingiu o maior valor em $87,74 \%$, o rejeito com $39,32 \%$, o papel $11,11 \%$, o plástico $15,20 \%$ e o alumínio $1,54 \%$. Vidro e outros foram encontrados em baixa quantidade, mas não devem ser desconsiderados.

Dessa forma, há necessidade de modificações no sistema de gerenciamento atual, para isso foram dadas algumas propostas que aprimorem o gerenciamento nas etapas existentes e implante as inexistentes.

A Universidade forma futuros profissionais, que poderiam ter exemplo de responsabilidade socioambiental no próprio ambiente acadêmico, por isso é importante que a instituição adote um sistema de gerenciamento ambiental, pois essa iniciativa torna a instituição bem vista pela sociedade como um todo, além de contribuir com questões ambientais, sociais e econômicas do local, que resulta em benefícios multidisciplinares.

\section{REFERÊNCIAS}

ASSOCIAÇÃO BRASILEIRA DE ENGENHARIA SANITÁRIA E AMBIENTAL. Modelo de Gestão Integrada dos Resíduos Sólidos Urbanos. Brasília: setembro de 2000.

CABRAL, E. Gestão de Resíduos Sólidos: Considerações sobre resíduos sólidos. Instituto Federal de Educação, Ciência e Tecnologia do Ceará. Disponível em: <http://www.deecc.ufc.br/Download/Gestao de Residuos Solidos PGTGA/CONSIDERAC OES SOBRE RESIDUOS SOLIDOS.pdf>. Acesso em: 24 jul. 2014.

GALVÃO, M. C. 0 tratamento legal dos resíduos sólidos. Portal de e-Governo, inclusão digital e sociedade do conhecimento. 2012. Disponível em: <http://www.egov.ufsc.br/portal/conteudo/ o-tratamento-legal-dos-res\%C3\%ADd uoss\%C3\%B3lidos>. Acesso em: 24 jul. 2014.

JACOBI, P. 2003. Educação ambiental, cidadania e sustentabilidade. Cadernos de Pesquisa, São Paulo, n. 118, mar., 2003. Disponível em: <http://dx.doi.org/10.1590/S010015742003000100008>. Acesso em: 24 jul. 2014.

Unoeste. Universidade do Oeste Paulista. Desenvolvida pela Faculdade de Informática de Presidente Prudente. Apresenta Campus II. Disponível em: <www.unoeste.br $>$. Acesso em: 16 mar. 2013. 